\title{
English teachers' awareness of using ICT in primary school of Shenzhen city in China
}

\author{
$\mathrm{Li} \mathrm{Li}^{1}$ \\ Kazi Enamul Hoque ${ }^{2}$ \\ Abdul Jalil Othman ${ }^{3}$ \\ And \\ Ahmad Zabidi Abdul Razak ${ }^{4}$ \\ ${ }^{1,2,3,4}$ Faculty of Education \\ University of Malaya \\ Kuala Lumpur, Malaysia
}

Doi:10.5296/ijld.v4i1.5028

URL: http://dx.doi.org/10.5296/ijld.v4i1.5028

\begin{abstract}
The study aims to assess the current situation concerning the use of ICT in Shenzhen city of China. This study was a survey using a set of questionnaire to investigate ICT as a tool in English teaching procedure in primary school in Shenzhen city. Data were collected from 172 teachers teaching English in primary schools. Data revealed that $61.0 \%$ of English teachers in primary schools of the respondents in Shenzhen have Bachelor Degrees, 29.1\% have Diplomas and $3.5 \%$ have got the Master Degree. There were $63.9 \%$ of teachers in the respondent were using English during their English class. There were $91 \%$ of respondents agree with that their principals had already informed them the ICT policies. More than $80.0 \%$ teachers strongly agreed that the ICT policies implementing in schools really helped their teaching. The findings have revealed the degree of teachers' awareness of ICT policy that can be considered as feedback to policy makers and implementers.
\end{abstract}

\section{Background}

Learning foreign languages has become one of the basic means for China's nation building (Yang 2002a). The commercial dominance of, first England, then America, in the twentieth century, has meant that English has become the global language (McKay 2002), a status that is further strengthened by the fact that the international communication system, particularly fuelled by the electronic revolution of the twentieth century (Crystal, 1997), operates primarily in English and further advantages academic communities which use that language (Altbach, 1998).

English plays an important role in the school curriculum as well as in people's daily lives in the People's Republic of China (PRC). As a required subject from primary to postgraduate school, it has a special position in Chinese education system (Cheng 2002). From the mid 1990s, together with Chinese and Mathematics, English has become one core element in China's university entrance examinations. Ford (1989: 2) once said that there were more Chinese studying English than there were Americans, with estimates ranging as high as 250 million Chinese students of English.

Today, the number can only increase as China officially begins to implement its policy to introduce English as a standardized compulsory subject for all participants in compulsory 
education (Ministry of Education, 2001). According to Lai (1993), significant progress is being made. In 2001, all schools in Shenzhen taught English in Primary school grade one, for instance. Nationwide, according to $\mathrm{Hu}$ (2002a), there are eight million primary school pupils were studying English as a school subject for two to three hours a week. The goal is to have English courses available for seven to nine years of the compulsory education stage and a total of ten to twelve years for those who go on to university (Cheng 2002: 258). With an estimated total of 121.57 million Chinese primary school students in 2002, according to official statistics, the challenge of providing English language instruction to them all is likely to be a demanding one.

Primary school is regarded as the most important education stage for students. So, theoretically the school leaders need to improve their school performance and technology, in order to improve school quality. The main question, however, do schools in Shenzhen consider the roles of ICT as the significance? If so, to what extent and how it works? Hence, it is imperative to conduct this study to know the situation and extent of the role of ICT use in primary English program, particularly in primary schools in Shenzhen China.

There are considerable different situation within and between countries, and between schools within countries. A small percentage of schools in some countries have put ICT into the curriculum, and demonstrate high levels of effective and appropriate ICT use to support and transform teaching and learning across a wide range of subject areas. Most schools in most countries, however, are in the early phase of ICT adoption, some enhancement of the learning process, some development of e-learning, but no profound improvements in learning and teaching.

On this background, the present Study on the Impact of ICT and New Media on Language teaching. The aim is to investigate the possibilities of ICT and new media as complements to traditional language teaching methods within and beyond the traditional framework of formal education systems, with the purpose to inform policymaking and future activity in the area of language teaching.

The study is going to assess the current situation concerning the use of ICT and new media for language learning, and cast light over future developments in this area. It concentrated particularly on identifying trends and practices beyond schools and universities, in working life and in personal life, including the use of ICT and new media in language learning in primary school. It will focus on language learners' behaviors, motivation and attitudes, possibilities for increased language learning outreach, as well as opportunities and challenges, demand and supply factors in the relevant markets.

In examining the development of ICTs in schools, an important distinction should be made. In the case of schools, teachers primarily use ICTs in the school as an instructional device. Students are more likely to use ICTs partly to learn.

\section{Shenzhen city of China as a case}

Shenzhen city is one of China's first special economic zone. After more than 20 years of development, Shenzhen has grown into a powerful city boasting the highest per capita GDP in China's mainland. 
Shenzhen city is a coastal city in South China; Shenzhen is located in southern Guangdong and eastern riverbank of the Pearl River. It's bordering Hong Kong southward via Shenzhen River with a 45-minute ride from its downtown to Hong Kong.

Shenzhen covers a total area of 1,952.84 square kilometers, including 395.81square kilometers designated as Shenzhen Special Economic Zone. Until 2009, Shenzhen city has about 20 million population, and 0.6 million primary students.

English nowadays assumes an important position in the school curriculum as well as in people's daily lives in the People's Republic of China (PRC). As a required subject from primary to postgraduate school, it has a special position in Chinese education (Cheng 2002). From the mid 1990s, together with Chinese and Mathematics, English has become one core element in China's university entrance examinations.

Since the promotion of Quality Education Project in China, using ICT into education has been given more focus as a specific topic among educational experts in China. School head-Responsibility System in China provides more space and freedom for school heads in managing and leading school in order to realize the successful education for students at primary level. So far, there is a limited number of researches about the use of ICT in English teaching in primary school in China which is comprehensive. This study will be conducted in Shenzhen, as a advanced city of Guangdong, in order to explicate the demographic profile and activities the teachers of using ICT in English teaching in primary schools.

When we are to identify the ways in which ICT influences teaching, it will not be sufficient to quantify and describe each of these factors in isolation and then seek correlations between them. We need to seek explicit evidence of interaction between them, by this research; the following objectives were formulated to achieve the aim:

\section{Objectives}

- To investigate the demography of English teachers in Shanzen city

- To investigate teachers' capability in using ICT

- To investigate teachers" awareness of ICT policy in primary schools;

\section{Methodology}

\section{$\underline{\text { Research Design }}$}

The primary data required for this study includes information regarding the ICT policies and location of ICT resources in primary school. The respondents for this study are teachers who teach English in some of the public primary schools in Shenzhen city, China. The main methodology to collect the primary data for this study was survey using a set of questionnaire to investigate ICT as a tool in English teaching procedure in primary school in Shenzhen city, China. The quantitative research is used because this approach can make the discovery of such information in the randomly selected primary school teachers that are comprehensive and pervasive; it is helpful for collect more information from teachers and students. Survey through internet has been the assistant method to collect data. Quantitative research design is an excellent way of finalizing results and proving or disproving a phenomenon. The structure has not changed for centuries, so is standard across many scientific fields and disciplines. 
After statistical analysis of the results, a comprehensive answer is reached, and the results can be legitimately discussed. Quantitative experiments also filter out external factor, if properly designed, and so the results gained can be seen as real and unbiased. Quantitative research involves counting and measuring of events and performing the statistical analysis of a body of numerical data (Smith, 1988). The main concerns of the quantitative paradigm are that measurement is reliable, valid, and generalizable in its clear prediction of cause and effect (Cassell \& Symon, 1994).

\section{Survey Instrument}

This questionnaire is about the role of ICT in English teaching process in primary school in Shenzhen city, China. It contains four sections.

The first section is demographics of teacher:

1. Gender

2. Age

3. Academic qualification

4. Teaching experience

Section 2-3 was made up statements that refer to survey questions regarding the ICT policies and the location of ICT resources in Primary schools of Shenzhen city.

These items will be graded based on a five-point Likert-type scale 5 to 1:5=strongly agree, $4=$ agree, $3=$ fair, $2=$ disagree, and 1=strongly disagree. As this study was conducted in China, the questionnaire used English. As the respondents are all teachers in English subject. So it is no need to translate into Chinese.

\section{Population and Sample}

The population of the study consisted some of the English teachers of the primary schools in Shenzhen city, China. Shenzhen city has 173 high classic primary schools. The sample made up of 218 English teachers out of the total population of 1090 English teachers from in Shenzhen city. The sample consisted of 218 English teachers from the public primary schools. 218 questionnaires were distributed to all the teachers in primary schools. 178 questionnaires were received. The response rate was $81.65 \%$. 6 questionnaires from the sample were rejected because they were incomplete or misunderstood. The final number of analyzed questionnaires was 172 .

\section{Findings}

Demographic profile for respondents

Table 4.1 shows the information about the gender of the respondents in the sample from the public primary schools in Shenzhen city, China. It can be seen that among the total of 189 respondents, $70.0 \%$ were females. The males were only $29.0 \%(n=50)$. The result reflected that there were more female English teachers than male English teachers in primary schools. 
Table 4.1 Frequency and Percentage by Gender of the Respondents

\begin{tabular}{llll}
\multicolumn{3}{c}{ Gender of the Respondents } \\
\hline \hline & & & Cumulative \\
& Frequency & Percent & Percent \\
\hline Males & 50 & 29.0 & 29.0 \\
Females & 122 & 71.0 & 100.0 \\
Total & 172 & 100.0 & \\
\hline \hline
\end{tabular}

Table 4.2 below shows the age factor of the teachers as respondents. The hugest percent $(69.8 \%)$ of the teachers were in 20-29 years old. And in the age from 30-39 groups, there were $18.6 \%$ teachers of the total respondents of 172. In 50-59 age group, there were only $2.3 \%$ among the respondents $(n=4)$. From the finding, it shows that $9.3 \%$ of teachers were between the ages of 40-49 years old.

Table 4.2 Frequency and Percentage of the Respondents' Age group

\begin{tabular}{lllll}
\multicolumn{5}{c}{ Age of the Respondents } \\
\hline \hline & $\begin{array}{l}\text { Age } \\
\text { group }\end{array}$ & Frequency & Percent & $\begin{array}{l}\text { Cumulative } \\
\text { Percent }\end{array}$ \\
\hline Valid & $20-29$ & 120 & 69.8 & 69.8 \\
& $30-39$ & 32 & 18.6 & 88.4 \\
& $40-49$ & 16 & 9.3 & 97.7 \\
& $50-59$ & 4 & 2.3 & 100.0 \\
& Above6 & & & \\
& 0 & 0 & 0 & \\
& Total & 172 & 100.0 & \\
Missing & System & 0 & 0 & \\
\hline \hline
\end{tabular}

From the Table 4.3 and Figure 4.1 it can be drawn that $41.9 \%$ of teachers $(n=72)$ had been teaching for $1-3$ years, and $29.1 \%(n=50)$ had been teaching for $4-6$ years. Those who had been teaching for 7 to 10 years, the frequency was 38 teachers $(22.1 \%)$. Those who had been in the profession for 11-13 years, the frequency were 7 teachers (4.0\%). Among them, only $2.9 \%(n=5)$ has more than 13 years of teaching experience. The result shows that more than 93\% teachers had been teaching between 1-10 years, and less than 7\% teachers had been teaching more than 10 years. 
Table 4.3 Years of Experience as Teachers of the Respondents

\begin{tabular}{|c|c|c|c|c|}
\hline & $\begin{array}{l}\text { Years of } \\
\text { experience }\end{array}$ & Frequency & Percent & $\begin{array}{l}\text { Cumulative } \\
\text { Percent }\end{array}$ \\
\hline \multirow[t]{6}{*}{ Valid } & $1-3$ & 72 & 41.9 & 41.9 \\
\hline & $4-6$ & 50 & 29.1 & 71.0 \\
\hline & $7-10$ & 38 & 22.1 & 93.1 \\
\hline & $11-13$ & 7 & 4.0 & 97.1 \\
\hline & above 13 & 5 & 2.9 & 100.0 \\
\hline & Total & 172 & 100 & \\
\hline Missing & System & 0 & 0 & \\
\hline Total & & 172 & 100.0 & \\
\hline
\end{tabular}

The table 4.4 shows that $61.0 \%$ of English teachers in primary schools of the respondents in Shenzhen have Bachelor Degrees $(n=105)$. Those who had Diplomas stand for $29.1 \%(n=50)$, the frequency of teachers who got the Master Degree and PhDs only consist for $3.5 \%$ and $1.1 \%$. The result also shows that $5.3 \%$ teachers had other professional level of teaching experience in the sample schools.

Table 4.4 Education level as Teachers of the Respondents

Education level as Teachers of the Respondents

\begin{tabular}{llll}
\hline \hline $\begin{array}{l}\text { Education } \\
\text { level }\end{array}$ & Frequency & Percent & $\begin{array}{l}\text { Cumulative } \\
\text { Percent }\end{array}$ \\
\hline Diploma & 50 & 29.1 & 29.1 \\
Degree & 105 & 61.0 & 90.1 \\
Master & 6 & 3.5 & 93.6 \\
PhD & 2 & 1.1 & 94.7 \\
Other & & & \\
professional & 9 & 5.3 & 100 \\
level & & & \\
Total & 172 & 100 & \\
System & 0 & 0 & \\
Total & & 172 & 100.0 \\
\hline \hline
\end{tabular}

This table shows that there were 72 teachers in the respondents were English teachers of Grade $1-2$, which stands for $41.9 \%$ of the total respondents. There were $32.6 \%(n=56)$ English teachers in the respondents were from grade $3-4$, and $25.5 \%(n=44)$ were teaching in grade 5-6. 
Table 4.5 Teaching grade as teachers in the respondents

\begin{tabular}{llll}
\multicolumn{3}{c}{ Teaching grades of the Respondents } \\
\hline \hline & Frequency & Percent & $\begin{array}{l}\text { Cumulative } \\
\text { Percent }\end{array}$ \\
\hline $\begin{array}{l}\text { Grade } \\
1-2\end{array}$ & 72 & 41.9 & 41.9 \\
Grade & 56 & 32.6 & 74.5 \\
3-4 & & & 100 \\
$\begin{array}{l}\text { Grade } \\
\text { 5-6 }\end{array}$ & 44 & 25.5 & \\
Total & 172 & 100 & \\
\hline \hline
\end{tabular}

Table 4.6 illustrates the English teachers' language during their teaching. There were $63.9 \%$ of teachers in the respondent were using English during their English class $(n=110)$. There was no teacher using Chinese in English classes. It shows that 29.0\% $(n=50)$ of English teachers from the respondent agreed that they were using both Mandarin and English language during their teaching. And there were 12 teachers out of the total respondents of 172 agreed that they were using Chinese-English in the teaching procedure.

Table 4.6 Teaching language during teaching

Teaching language during teaching of the Respondents

\begin{tabular}{|c|c|c|c|c|}
\hline & $\begin{array}{l}\text { Teaching } \\
\text { language }\end{array}$ & Frequency & Percent & $\begin{array}{l}\text { Cumulative } \\
\text { Percent }\end{array}$ \\
\hline \multirow[t]{5}{*}{ Valid } & Chinese & 0 & 0 & 0 \\
\hline & English & 110 & 63.9 & 63.9 \\
\hline & $\begin{array}{l}\text { Mandarin\& } \\
\text { English }\end{array}$ & 50 & 29.1 & 94.0 \\
\hline & $\begin{array}{l}\text { Chinese- } \\
\text { English }\end{array}$ & 12 & 6.0 & 100 \\
\hline & Total & 172 & 100 & \\
\hline Missing & System & 0 & 0 & \\
\hline Total & & 172 & 100.0 & \\
\hline
\end{tabular}

Teachers' Capability with ICT

This table (4.7) of data illustrates the teachers' capability with ICT in their working. The result shows that there were no teachers not familiar or not at all familiar with ICT resources. There were $41.9 \%$ of teachers very familiar with ICT equipments during their teaching. $45.3 \%(n=78)$ teachers were familiar with ICT using into English teaching procedure. The rest $12.8 \%$ teachers in the respondents said they were fair with ICT resources in English teaching. It shows that primary English teachers of the respondents in Shenzhen city were quite skilled in ICT resources. 
Table 4.7 Teachers' capability with ICT

\begin{tabular}{lllll}
\multicolumn{4}{l}{ Teachers' capability with ICT of the Respondents } \\
\hline \hline & $\begin{array}{l}\text { ICT } \\
\text { capability }\end{array}$ & Frequency & Percent & $\begin{array}{l}\text { Cumulative } \\
\text { Percent }\end{array}$ \\
\hline Valid & $\begin{array}{l}\text { Very } \\
\text { familiar }\end{array}$ & 72 & 41.9 & 41.9 \\
& Familiar & 78 & 45.3 & 87.2 \\
& Fair & 22 & 12.8 & 100 \\
& Not familiar & 0 & 0 & \\
& $\begin{array}{l}\text { Not at all } \\
\text { familiar }\end{array}$ & & 0 & \\
& Total & 172 & 100 & \\
Missing & System & 0 & 0 & \\
Total & & 172 & 100.0 & \\
\hline \hline
\end{tabular}

The teachers' awareness of the policies of ICT in primary schools

Figure 4.1 describes teachers' awareness of ICT policies in four areas.

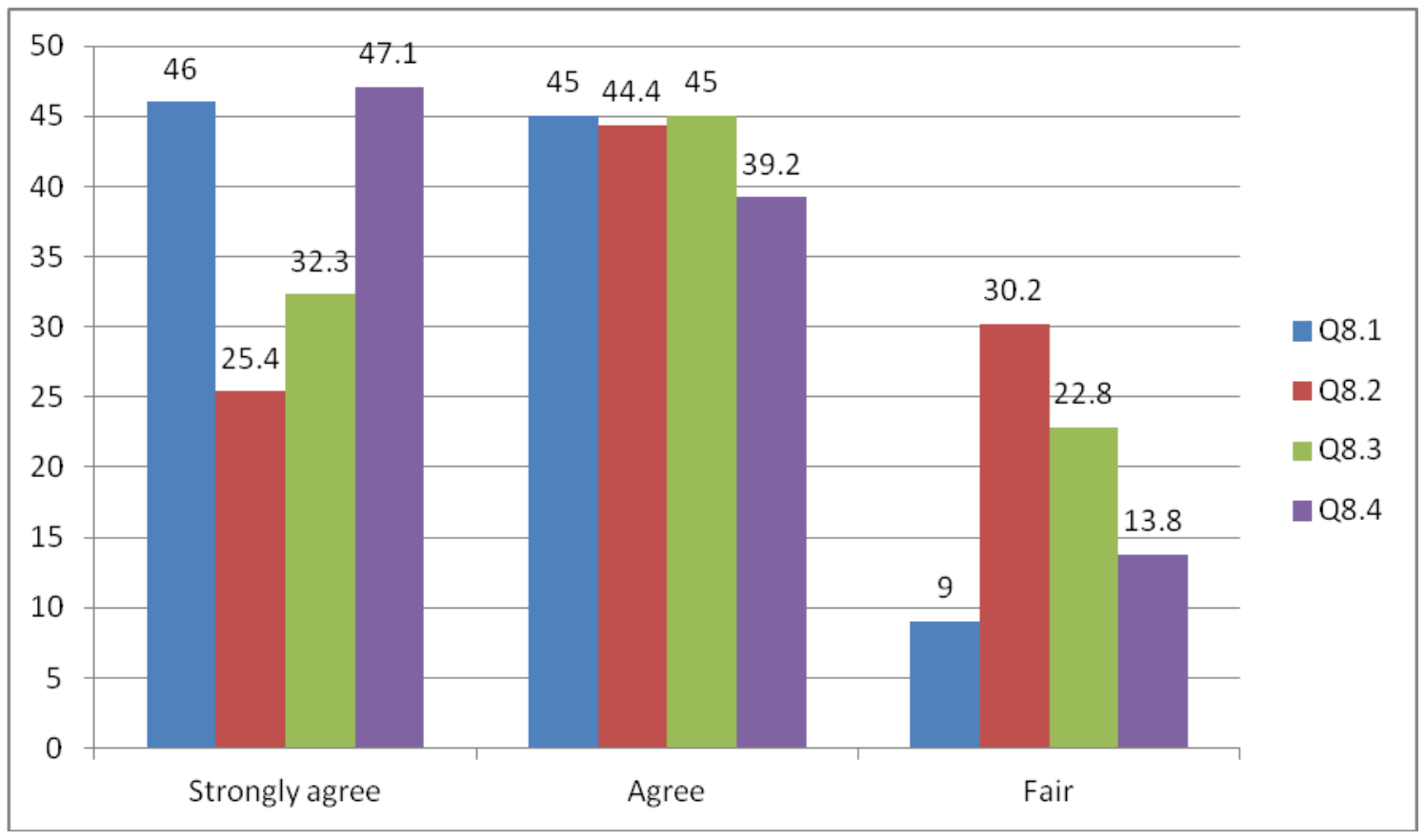

Figure 4.1 Teachers' awareness of the ICT policies

Information regarding ICT policy from the Principal (Q8.1): There were $46 \%$ of respondents strongly agree with that their principals had already informed them the ICT policies. $45 \%$ of respondents agreed with this statement. And 9\% of teachers of all the 172 respondents felt the information they received were fair. No respondent has chosen disagree or strongly disagree. 
Information regarding ICT policies from the Government (Q 8.2): Of all the respondents, $44.4 \%$ teachers felt agree with the statement. $25.4 \%(n=48)$ respondents strongly agree that they were totally understand the policies from government. Meanwhile, $30.2 \%$ of the respondents felt fair of the statement. And there was no teachers chosen disagree and strongly disagree. The results had shown that all the respondents known about the ICT policies from government.

Teachers' idea on implementation of ICT policies in School (Q 8.3): There has 32.3\% respondents strongly agreed with this item, $45 \%$ respondents strongly agree with that their schools were implementing the ICT policies. And 22.8\% teachers of the respondents have chosen "No idea". No respondents answer "disagree" or "strongly disagree". This indicates that the ICT policies of respondents' schools were widely implementing.

Teachers' opinion on using ICT (Q.8.4): More than $47.1 \%$ teachers strongly agreed that the ICT policies implementing in schools really helped their teaching, 39.2\% respondents agreed with this item, there were $13.8 \%$ chosen "no idea". No negative answers for this item. The results shows that the ICT policies in Education in schools supported and helped teachers teaching in a highly extent.

\section{Discussion and Conclusion}

\section{Teaching Profession in Shenzhen, China}

Regarding research of the general information of the teachers in the respondent:

- Teachers working at primary level are predominantly female.

- Most of the primary school teachers working have the degrees with specialize of the subject they are teaching.

- Primary English teachers in Shenzhen city, China typically give class to 2-3 classes of children all day.

- Most primary schools are still got the exam pressure compared to secondary level.

- Children are in relatively small but well equipment primary schools.

Educators believe that school and education are the vital means of change and development and teacher quality of life (Sufean, 2006b; Bush, 2004; Davies, 2002; Blasé and Blasé, 2002). In the schools, it is the teaching and learning outcomes that determine the quality of education, instruction and learning. For the teaching part, teachers' expertise is the key point to effect education quality.

Firstly, it shows that the number of female teachers was greater than the number of male teachers. $69.8 \%$ of the respondents were female and only $30.2 \%$ were male. It has shown that this was consistent with other findings that indicated more female than male are in the teaching profession in primary level. Probably, there were some factors behind this phenomenon. The important factor was the stability of this job comparing with other kind of jobs that have high risk in the current society, and this factor was the priority for women in profession. Teacher's salary and bonus in public schools were not very high, but at least they did not need to worry about they may lose the job one day. However, male usually did not like teaching so much. In their eyes, stability of the job is not so important and necessary in the life. Because this job has no challenge for most males and hence they prefer to do other jobs full of variety and 
excitement. Hence it can be said that there is a tendency in future in Shenzhen that is more and more female are going to be teachers in schools.

Secondly, most of the teachers are from the age group of below 30 years, which is the young-aged group than from other age groups. So we can see that primary English teachers are in the young-aged trend. As English is the newly second language in China, young teachers are more profession in this subject. Thirdly, most respondents are junior teachers who have worked below10 years. It is clearer that most teachers hold a bachelor's degree while only $1.1 \%$ masters degree. Fourthly, the respondents in this study are quite average from 1-6 grade in primary schools. And the teachers can use English or both English and mandarin as the main language during their teaching process. Lastly, teachers' capabilities with ICT are quite high in primary schools in Shenzhen city, China. None of the teachers in the respondents have any capability in ICT.

\section{Teachers' awareness of the ICT policies}

It goes without saying that in order to enable teachers to implement ICT in their daily teaching practice, several preconditions have to be met. Among these are access to hardware, the availability of appropriate educational software, the availability of adequate teacher training and support, and room for ICT-related activities in the curriculum. The government's policy as well as the school policy with regard to ICT plays an important role in this respect.

Regarding research question 1 , based on the analysis of data, the impact of ICT on primary schools, teachers and learners cannot be seen in isolation, but only in its wider educational context. The policy-maker survey specifically looked at the main characteristics of primary education systems in Shenzhen city, analyzed national policies for ICT in education, educational priorities and the role of ICT and the primary school curricula.

The common policy approach in China is to include ICT in general education policy and to have a specific ICT policy for all schools. And usually aimed at improving teacher competence and infrastructure (on the assumption than improved learning outcomes will follow). Although there is evidence that leadership and changing educational culture and pedagogy bring about the most effective conditions for ICT use and impact, few strategies target leadership and change in educational culture. It is interesting to note that the frequently reported impacts of ICT in primary schools, and reasons for using ICT, is increased pupil motivation and engagement. The use of ICT to improve the management and administration of schools is less complex and benefits from such deployment are more proven than using ICT in teaching and learning

Policies to reform the curriculum, pedagogy and assessment are uncommon, despite the fact that they are as important a success factor as infrastructure, subject content and teacher education and technical support. The engagement of parents, employers, the media, politicians and the wider community is important to articulate expectations, support the schools, and apply pressure for ICT change. There is a split in the policy survey analysis on the issue of whether computers should be distributed in classrooms or clustered in labs, but it disappears in the this study in Shenzhen city with high levels of ICT favor into classrooms.

Kozma (2005) also suggests that ICT implementing in education as a quest for quality learning: Schools should profoundly revise present teaching practices and resources to create more effective learning environments and improve life-long learning skills and habits in their students. 
In conclusion, this research has brought some enlightenment for improving the teachers' capability with new technology in primary schools in Shenzhen. The teachers' role is rapidly evolving, requiring many skills. More than ever it is evident that one person cannot do it all, so effective teachers can share the many responsibilities with others in school community. Being a good technology teacher in primary school in Shenzhen is not easy but important task. There are many new challenges and evolving changes in primary English teaching procedure today and in the future, and thus school teachers must be able to harness new opportunities and make their teaching more effective and motivation.

\section{References}

1. Yang, Rui, 2002a, Third Delight: The Internationalisation of Higher Education in China, Routledge, New York.

2. Altbach, Philip G. (1998). Comparative higher education: knowledge, the university and development, Comparative Education Research Centre, University of Hong Kong

3. Cheng, Zhao-xiang (2002). English departments in Chinese universities: purpose and function, World Englishes,.21(2), 257-267

4. Cassell, C, \& G. Symon, eds. (1994). Qualitative methods in organizational research: A practical guide. London: Sage

5. Crystal, D. (1997).English as a global language. Cambridge: Cambridge University Press.

6. Hu, Guang-wei, (2002a). Recent important developments in secondary English language teaching in the People's Republic of China, Language, Culture and Curriculum, (15), $130-49$

7. Kozma, R. (2005). "ICT, Education Reform and Economic Growth". International Education Journal 4(2): 244-280

8. Lai, Eva F. K. (1993). Report of a workshop in China, In Chinese University of Hong Kong (ed.), Occasional papers in English language teaching, Chinese University of Hong Kong (93-102).

9. McKay, Sandra Lee. (2002), Teaching English as an international language: rethinking goals and approaches, Oxford University Press, Oxford.

10. Smith M.J. (1988). Contemporary communication research methods. Belmont, CA: Wadsworth, Inc.

11. Sufean Hussin (2006b). Administration of Educational Development. Kuala Lumpur: PTS Publisher 